\title{
PORTRAYAL OF AUTISM SPECTRUM DISORDERS AND RELATED TREATMENTS IN QATAR'S PRINTED MEDIA
}

\author{
M. Zolezzi, H. Saadia, S. Habib; College of Pharmacy, QU Health, Qatar University, Doha, Qatar
}

\section{Background}

- Autism spectrum disorder (ASD), is a neurodevelopmental condition. Symptoms range from challenges with social interaction, verbal, and non-verbal communication, and restricted or repetitive behavioral patterns. In Qatar, the prevalence rate is 6 to 7 children per 1000 in the low probability group (children in mainstream education).

- Although considerable progress in the diagnosis and treatment of ASD has emerged over the last decade, negative media stereotypes about ASD and its treatments are amongst the most hurtful and socially limiting stigma experiences reported by mental health service consumers and family members.

- The topic of treatment for ASD has all the ingredients for a sensational media product. Although there is an inherent intent to convey information, there is also potential for influencing consumers on treatments that may not necessarily be evidence-based.

\section{Study Objectives}

- To have a better understanding of Qatar's media portrayal of ASD.

- To evaluate how does Qatar's media consider the evidence behind the available treatments for ASD.

- To identify areas in need of improvement of the public's understanding of ASD and its treatments in Qatar.

\section{Project Questions}

- How is ASD portrayed by Qatar's media?

- How does media describe the benefits and risks associated with ASD treatments?

- Does the media consider the scientific evidence behind ASD treatment?

\section{Methods}

Figure 1: Research strategy

\section{Retrospective, quantitative \&} qualitative analysis

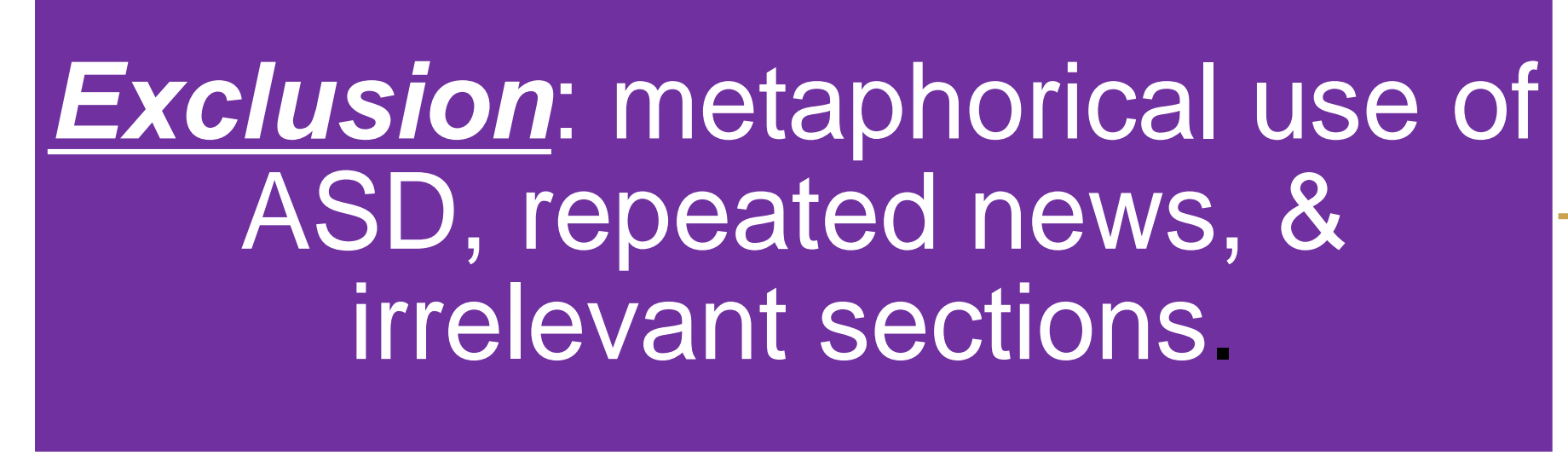

Inclusion: Arabic \& English

Qatari daily newspaper articles

Keywords: ASD, autism, autis, توحد

Quantitative analysis

(using SurveyMonkey®, Excel and SPSS)
Qualitative analysis (using predetermined coding approach)
Treatments sub-group analysis

(guidelines and primary literature)

\section{Methods Cont'd}

- As illustrated in Figure $1 \mathrm{~A}$, a retrospective, quantitative, and qualitative content analysis of articles printed in English and Arabic newspapers over one year was used.

- Quantitative descriptive analysis was employed to examine the extent of media coverage.

- A pre-determined coding approach derived from an extensive review of the literature was used to examine the discourse tone and assess the stigmatization of the main messages on the text.

- Articles discussing ASD treatments were analyzed separately, by reviewing the scientific evidence as outlined in the Qatar and the American Academy of Pediatrics (AAP) ASD treatment guidelines.

\section{Results}

- A total of 178 ASD-related articles were found in 1 year of published articles.

- Quantitative analysis revealed that the overall attractiveness of ASD-related articles was poor, the majority were in relation to general news or local events and had a limited focus on the scientific aspects of this condition or its treatments.

- The discourse analysis revealed significantly more stigmatizing statements in articles in Arabic compared to those in English newspapers.

- Table 1 provides a summary of the various ASD-related treatments covered in Qatar's newspapers. Based on current practice guideline recommendations, the majority of the treatments discussed had insufficient or lacked scientific evidence.

\section{Table 1: ASD treatiments}

\section{Types of treatments mentioned in Qatar's newspapers}

\begin{tabular}{|c|c|}
\hline Nutritional therapy (diets) & \multirow{6}{*}{$\begin{array}{l}\text { Other therapies: } \\
\text { - Early intervention } \\
\text { - Educational, occupational, physical, } \\
\text { speech-language, oxygen, and social } \\
\text { skills therapies. } \\
\text { - Stem cell transplant }\end{array}$} \\
\hline Medication treatment & \\
\hline Behavioral management & \\
\hline Parent-mediated therapy & \\
\hline Music therapy & \\
\hline et therapy, Equine thera & \\
\hline
\end{tabular}

\section{Conclusions}

- Results from this study suggest that there is a need to improve how the print media addresses ASD.

- More scientific and responsible writing is needed, particularly when recommending treatments for this condition.

- Qatar has recently implemented the "National Autism Strategy", which aims for inclusion of ASD in the society. Collaborative efforts with the media will be necessary to achieve this aim.

- It is important for the journalists to realize that they have a responsibility to provide the public with unbiased and accurate information regarding this condition.

\section{Acknowledgements}

We would like to thank Dr. Suhad Daher-Nashif at the College of Medicine, Qatar University, for helping us in the cross-checking for the qualitative discourse analysis of Arabic articles. 